\title{
Preservation of the Aortic Root During Type A Aortic Dissection Surgery: An Effective Strategy?
}

\author{
Simon Dang Van, MD ${ }^{1}$ jihed Laribi, $\mathrm{MD}^{1}$ Frédéric Pinaud, $\mathrm{MD}, \mathrm{PhD}^{1}$ Patrice Binuani, $\mathrm{MD}^{1}$ \\ Serge Willoteaux, MD, $\mathrm{PhD}^{2}$ Christophe Baufreton, $\mathrm{MD}, \mathrm{PhD}^{1,3, *}$ Olivier Fouquet, $\mathrm{MD}, \mathrm{PhD}^{1,3, *}$
}

${ }^{1}$ Department of Cardiac Surgery, University Hospital of Angers,

Address for correspondence Simon Dang Van, MD, Service de Angers, France

2 Department of Radiology, University Hospital of Angers, Angers, Chirurgie Thoracique et Cardiovasculaire, CHU d'Angers, 4 rue Larrey, France 49933 Angers Cedex 09, France (e-mail: Simon.DangVan@chu-angers.fr).

${ }^{3}$ Mitovasc Institute INSERM U1083 UMR-CNRS 6214, University Hospital of Angers, Angers, France

Aorta (Stamford) 2021;9:67-75

\begin{abstract}
Keywords

- aortic dissection

- aortic root

- late reoperation

- supracoronary aortic replacement

Background Management of the aortic root during acute Type A aortic dissection (TAAD) repair remains controversial in term of long-term evolution and reoperation. The aim of this study was to assess the long-term outcomes of the aortic root after conservative management during primary surgery.

Methods One hundred sixty-four consecutive patients were included in this monocentric retrospective study. The primary endpoint was reoperation on the aortic root during long-term follow-up. Forty-six patients had aortic root replacement (ARR) and 118 had supracoronary aortic replacement (SCR). The 10-year survival, occurrence of significant aortic regurgitation, and radiologic aortic root dilatation in each group were assessed during follow-up.

Results Patients from ARR group were younger than those from SCR group $(p<0.0001)$. Median follow-ups of ARR group and SCR group are 4.4 (interquartile range [IR]: 2.6-8.3) and 6.15 (IR: 2.8-10.53) years, respectively. Reoperation of the aortic root during long-term follow-up was similar in both groups (ARR group: 5.1\%, SCR group: 3.3\%, $p=0.636$ ). The 10 -year survivals of ARR and SCR groups were $64.8 \pm 12.3 \%$ and $46.3 \pm 5.8 \%(p=0.012)$, respectively. Long-term significant aortic regurgitation occurred in one patient (1.7\%) and seven patients (7.6\%) of the ARR and SCR groups $(p=0.176)$, respectively. Radiologic aortic root diameters in the SCR group were similar between postoperative period and follow-up studies $(p=0.58)$. Reoperation on the distal aorta $(p=0.012)$ and patent radiologic false lumen of the descending aorta $(p=0.043)$ were independent risk factors of late death.

Conclusion SCR is an effective technique for primary TAAD surgery and does not increase the rate of late reoperation on the aortic root.
\end{abstract}

* The last two authors contributed equally to the study.

received

February 28, 2020 accepted after revision October 2, 2020 published online October 7, 2021
DOI https://doi.org/ $10.1055 / \mathrm{s}-0041-1725074$. ISSN 2325-4637.
(C) 2021. The Author(s).

This is an open access article published by Thieme under the terms of the Creative Commons Attribution License, permitting unrestricted use, distribution, and reproduction so long as the original work is properly cited. (https://creativecommons.org/licenses/by/4.0/)

Thieme Medical Publishers, Inc., 333 Seventh Avenue, 18th Floor, New York, NY 10001, USA 


\section{Introduction}

Acute Type A aortic dissection (TAAD) remains a catastrophic disease with a high rate of mortality that requires emergency surgery. One of the most complex aspects of this surgery is to determine the extent of the resected ascending aorta. A conservative approach with supracoronary replacement (SCR) of the ascending aorta and resuspension of the aortic valve is a widespread technique that provides acceptable early mortality rate. ${ }^{1}$ However, preserving the aortic root during surgery for TAAD may expose to several concerns during long-term follow-up. Indeed, recurrence of aortic regurgitation, secondary aortic root aneurysm, proximal false lumen aneurysm, and recurrent dissection of the aortic root are described unfavorable outcomes after TAAD surgery treated with a conservative technique. ${ }^{2}$ Replacement of the aortic root (such as Bentall, Tirone David, or Yacoub procedures), may prevent late reoperation on the aortic root through their total resection of the pathologic aortic wall, including sinus of Valsalva., ${ }^{3,4}$ On the other hand, such techniques are more complex than SCR and may increase perioperative morbidity and mortality. ${ }^{5}$ A few studies suggest that a more extensive approach to the aortic root during TAAD surgery provides excellent outcome and decreases aortic root complications and late reoperation. ${ }^{4,6}$ However, others studies ${ }^{7}$ do not show increased early and late mortality for proximal reoperation of the aortic root after a previous TAAD conservative surgery on the aortic root.

The aim of this study was to compare the long-term results and outcomes of aortic root replacement (ARR) versus supracoronary replacement during TAAD repair.

\section{Materials and Methods}

\section{Population}

Between January 1990 and December 2014, 164 consecutive patients underwent aortic surgery for TAAD at the University Hospital of Angers. A patient database was constituted retrospectively using clinical records, imaging, and operative reports. Patients were divided into following two groups according to the operative management of the aortic root during TAAD surgery: (1) SCR of the ascending aorta and (2) ARR. Individual consent and institutional review board approval were waived because they were not required by the ethics committee according to French regulation, concerning this retrospective observational study using data collected from clinical patient's records only.

\section{Surgical Technique}

According to surgeon's discretion, arterial cannulation sites were the femoral or the axillary arteries. Venous drainage was ensured by simple or double venous cannulation (superior and inferior vena cava, femoral vein and superior vena cava, or a simple right atrial cannulation). Cerebral protection during circulatory arrest for open arch surgery was performed with moderate $\left(25-28^{\circ} \mathrm{C}\right)$ or deep hypothermia $\left(18-20^{\circ} \mathrm{C}\right)$. Retrograde cerebral perfusion through the superior vena cava ${ }^{8}$ was mostly performed until 2010 . Antegrade cerebral perfusion through the right axillary artery, the left common carotid, and/or the right brachiocephalic artery was the preferred strategy of cerebral perfusion since 2010. Cerebral perfusion flow rate was $10 \mathrm{~mL} / \mathrm{kg} / \mathrm{min}$. No visceral perfusion was performed during circulatory arrest. If needed, the proximal and/or distal residual aortic wall was repaired with surgical glue (Biolgue, Cryolife, Kennesaw, GA).

In case of nonconservative surgery of the aortic root, modified Bentall procedure or remodeling or inclusion technique of the aortic root described by David and Feindel ${ }^{9}$ and Sarsam and Yacoub ${ }^{10}$ was performed.

\section{Postoperative Management}

Postoperative outcomes were retrospectively collected from the patient's clinical file. An aortic computed tomography or magnetic resonance imaging and a transthoracic echocardiography were performed at discharge from hospital.

\section{Follow-up}

Clinical and radiological follow-ups were performed for all patients alive at discharge from hospital. Data were collected from the patient's clinical record. Data from patients lost to direct follow-up were collected by telephone interview from their attending physicians or cardiologists. Radiographic analysis of the aortic imaging was performed by standardized measures of the aortic root, ascending aorta, aortic arch, and descending aorta and compared between the postoperative and follow-up periods. Patency of the residual false lumen and perfusion deficits were also analyzed. Patency of the false lumen was divided into two groups as follows: patent false lumen or a partially thrombosed lumen versus a completely thrombosed false lumen. All measures were obtained after two-dimensional (2D) and three-dimensional (3D) image reconstruction with Osirix software (Pixmeo SARL, Bernex, Switzerland) employing orthogonal views of the different segments of the aorta to provide reliable diameters.

\section{Endpoints}

The primary endpoint was the occurrence of reoperation of the aortic root. Secondary endpoints were death during hospitalization and follow-up, occurrence of aortic regurgitation $\geq$ grade 2 , reoperation of the distal aorta, and aortic root dilatation (defined as a maximal diameter at the sinuses of Valsalva in relation to body surface area higher than $21 \mathrm{~mm} / \mathrm{m}^{211}$ ). In-hospital mortality was defined as the occurrence of death within 30 days after surgery. Patients dead within these 30 days were excluded from the long-term analysis. Postoperative and late radiologic diameters of aortic root were compared between groups.

\section{Statistical Analysis}

Statistical analysis was performed using SPSS Statistics software (IBM Corporation, New York, NY). Categorical variables were expressed as percentages. Continuous variables were reported as mean \pm standard deviation (SD). Continuous variables were compared between groups using t-test or Mann-Whitney $U$-test when nonnormally distributed, whereas categorical variables were compared using the 
Chi-square test or the Fisher's exact test when appropriate. Event-free survival curves were calculated using the KaplanMeier method. Survival curves were compared using the logrank test. The influence of the type of surgery on postoperative death and freedom from aortic root pejorative evolution was assessed by univariate and multivariate Cox analyses, adjusted on confounding factors. A $p$-value of $<0.05$ was used for statistical significance.

\section{Results}

\section{Preoperative Characteristics}

One hundred and sixty-four patients were included in the study. Patient's baseline characteristics are summarized in -Table 1. Mean age of the entire cohort was $61.12 \pm 14.1$ years. Forty-six patients and 118 patients underwent ARR and SCR, respectively. Patients from the ARR group were younger (ARR group: $51.65 \pm 16.35$, SCR group: $64.81 \pm 11.17, p<0$ 0.0001), had more annuloaortic ectasia disease (ARR group: $20.5 \%$, SCR group $0.9 \%, p<0.0001$ ) and had more significant aortic regurgitation $\geq 2$ (ARR group: $65.9 \%$, SCR group $44.4 \%, p=0.016$ ) than patients from the SRC group. Preoperative data imaging (-Table 2) showed more primary intimal tear in the sinus of Valsalva in the ARR group than in the SCR group (ARR group: $43.2 \%$, SCR group: $13.6 \%, p<0.0001)$ and more patent false lumen in the sinus of Valsalva (ARR group: $86.8 \%$, SCR group: $56 \%, p=0.001$ ).

\section{Operative Data}

Operative data are summarized in -Table 3. Between 1990 and 2000, 37 patients underwent surgery for TAAD in our institution and 8 patients (21.6\%) of them had ARR with the Bentall technique during this period. Between 2001 and 2014, 127 patients were operated for TAAD and 38 patients (29.9\%) of them had ARR with the modified Bentall technique, Yacoub technique, and Tirone David technique. Surgical observation of the dissected structures showed more dissected sinus of Valsalva in the ARR group than in the SCR group (SCR group: $1.24 \pm 1.20$, ARR group: $1.80 \pm 1.22, p=0.009$ ). In the ARR group, three patients (6.5\%) had a Yacoub procedure, 19 patients $(41.3 \%)$ had the Tirone David procedure and 24 patients (52.2\%) had the Bentall procedure. Of the 24 patients, 10 patients $(21.8 \%$ ) had a biological aortic valve prosthesis and $14(30.4 \%)$ had a mechanical aortic valve prosthesis. Ten patients of the SCR group (8.4\%) underwent aortic valve replacement (AVR). Cardiopulmonary bypass time and cross clamp time were significantly longer in ARR group $(p=0.002$ and $<0.0001$, respectively). Eighty-four patients (71.2\%) of the SCR group had additional glue used to reinforce the aortic root. Of them, 61 patients (72.6\%) had Bioglue (Bioglue Surgical Adhesive, Cryolife Inc., Kennesaw, GA), 22 patients (26.2\%) had Tissucol Kit (Baxter, Guyancourt 78280, France), and 1 patient (1.2\%) had Fibrogel. No difference was observed in terms of reoperation on the aortic root during follow-up with or without previous use of biological glue in the SCR group $(p=0.497)$. There was no difference concerning the management of the distal anastomosis between the two groups. Hemiarch replacement was the most performed technique in the management of the distal anastomosis in both groups. Antegrade cerebral perfusion was more frequently used in the ARR group than in the SCR group $(p=0.029)$.

\section{Postoperative Outcomes}

Postoperative data are summarized in -Table 4 . There was no difference observed between the two groups concerning the in-hospital mortality ( $p=0.091)$, the intensive care unit length of stay ( $p=0.230)$, the total length of stay $(p=0.262)$, pejorative neurological event, and reoperation for major bleeding $(p=0.684)$. Less postoperative renal failure was observed in the ARR group $(p=0.001)$. There was no difference between the two groups concerning early postoperative aortic regurgitation $\geq$ grade $2(p=0.435)$.

\section{Reoperation of the Aortic Root}

Freedom from reoperation on the aortic root period is summarized in - Fig. 1. One patient of the ARR group was lost to followup. Two patients (4.8\%) from the ARR group were reoperated on the aortic root, one patient underwent aortic valve replacement 21 years after primary surgery for aortic stenosis of the biological prosthesis and another patient had aortic endocarditis on a biological prosthesis requiring aortic valve replacement. Both patients were alive at the end of follow-up without significant aortic regurgitation. Three patients underwent reoperation on the aortic root in the SCR group (3.3\%), two patients $(2.2 \%)$ presented pseudo aneurysm of the proximal anastomosis and one $(1.1 \%)$ patient presented pseudoaneurysm of the right coronary artery. The two patients with proximal anastomosis aneurysm died after the reoperation from multiorgan failure. The patient with the right coronary anastomosis aneurysm was reoperated successfully 6 years after primary surgery. He died 3 years after reoperation because of a recurrent distal aortic anastomosis aneurysm compressing the upper airways. Mean periods before reoperation in the ARR group and SCR group were $14.7 \pm 6.3$ and $5.53 \pm 2.42$ years $(p=0.400)$, respectively. There was no difference between the two groups concerning reoperation of the aortic root during long-term follow-up $(p=0.636)$.

\section{Survival Analysis}

Overall survival is shown in - Fig. 2A. Data from 132 patients were available during follow-up. Mean survival was $11.10 \pm 0.97$ years for the entire cohort. Overall survival at 1,5 , and 10 years was $77.1 \pm 3.3 \%, 70.8 \pm 3.7 \%$, and $53.2 \pm 5.1 \%$, respectively. Survival of each group is shown in - Fig. 2B. The 5-year survival was $80.6 \pm 5.6 \%$ in the ARR group and $66.4 \pm 4.5 \%$ in the SCR group $(p=0.012)$. The 10 year survival was $64 \pm 12 \%$ and $46 \pm 5.8 \%(p=0.012)$, respectively, in the ARR and SCR groups. Median follow-up of the ARR and the SCR groups is 4.4 (interquartile range [IR]: 2.6-8.3) and 6.15 (IR: $2.8-10.53 ; p=0.241$ ) years, respectively. Mean survivals for ARR and SCR groups were $18.56 \pm 2.23$ and $8.77 \pm 0.69$ years $(p=0.002)$, respectively.

\section{Aortic Regurgitation $\geq$ Grade 2}

Freedom from new-onset aortic regurgitation $\geq 2$ is shown in - Fig. 3A. Data were available for 34 (82.9\%) patients of the 
70 Type A Aortic Dissection and Aortic Root Surgery Van et al.

Table 1 Population baseline characteristics

\begin{tabular}{|c|c|c|c|c|c|}
\hline & \multicolumn{2}{|c|}{ SCR group $(n=118)$} & \multicolumn{2}{|c|}{ ARR group $(n=46)$} & \multirow[t]{2}{*}{$p$-Value } \\
\hline & $n$ & $\%$ & $n$ & $\%$ & \\
\hline Male gender & 71 & 60.2 & 40 & 87 & 0.001 \\
\hline Age (y) & \multicolumn{2}{|c|}{$64.81 \pm 11.17$} & \multicolumn{2}{|c|}{$51.65 \pm 16.35$} & $<0.0001$ \\
\hline \multicolumn{6}{|l|}{ Cardiovascular risk factors: } \\
\hline Hypertension & 88 & 77.2 & 24 & 54.5 & 0.006 \\
\hline Smoking & 32 & 28.6 & 12 & 27.9 & 0.935 \\
\hline Obesity & 31 & 27 & 5 & 11.4 & 0.036 \\
\hline Dyslipidemia & 37 & 32.2 & 4 & 9.1 & 0.002 \\
\hline Diabetes & 12 & 10.4 & 4 & 9.1 & 1 \\
\hline Heredity of aortic disease & 7 & 6.1 & 10 & 22.7 & 0.007 \\
\hline Height (cm) & \multicolumn{2}{|c|}{$167.34 \pm 8.45$} & \multicolumn{2}{|c|}{$174.11 \pm 9.04$} & $<0.0001$ \\
\hline Weight (kg) & \multicolumn{2}{|c|}{$78.17 \pm 18.14$} & \multicolumn{2}{|c|}{$76.78 \pm 12.43$} & 0.637 \\
\hline Body surface area $\left(\mathrm{m}^{2}\right)$ & \multicolumn{2}{|c|}{$1.85 \pm 0.30$} & \multicolumn{2}{|c|}{$1.90 \pm 0.17$} & 0.341 \\
\hline Marfan disease & 2 & 1.7 & 4 & 9.1 & 0.05 \\
\hline Bicuspid aortic valve & 3 & 2.7 & 5 & 11.4 & 0.043 \\
\hline Annuloaortic ectasia & 1 & 0.9 & 9 & 20.5 & $<0.0001$ \\
\hline Pregnancy & 0 & 0 & 1 & 2.2 & 0.278 \\
\hline latrogenic dissection & 4 & 3.4 & 0 & 0 & 0.576 \\
\hline \multicolumn{6}{|l|}{ Medical history of: } \\
\hline Obliterant arteriopathy & 9 & 7.8 & 1 & 2.3 & 0.286 \\
\hline Chronic renal failure & 2 & 1.7 & 3 & 6.8 & 0.130 \\
\hline Obstructive chronic bronchitis & 6 & 5.2 & 1 & 2.3 & 0.674 \\
\hline Gastroduodenal ulcer & 4 & 3.5 & 1 & 2.3 & 1 \\
\hline Cancer & 7 & 6.1 & 6.1 & 0 & 0.191 \\
\hline Myocardial infarction & 5 & 4.3 & 0 & 0 & 0.323 \\
\hline Previous cardiac surgery: & 5 & 4.3 & 2 & 4.4 & 1 \\
\hline Aortic valve surgery & 4 & 3.4 & 1 & 2.3 & 1 \\
\hline Aortic surgery & 1 & 0.9 & 1 & 2.3 & 1 \\
\hline NYHA status $\geq 2$ & 10 & 8.5 & 5 & 11.1 & 0.560 \\
\hline Preoperative shock/tamponade & 29 & 24.6 & 10 & 21.7 & 0.701 \\
\hline Mesenteric ischemia & 6 & 5.1 & 0 & 0 & 0.188 \\
\hline Limb ischemia & 15 & 12.7 & 4 & 8.9 & 0.497 \\
\hline Acute aortic dissection & 110 & 93.2 & 45 & 97.8 & 0.447 \\
\hline $\operatorname{LVEF}(\%)$ & \multicolumn{2}{|c|}{$56.97 \pm 14.49$} & \multicolumn{2}{|c|}{$61.32 \pm 3.94$} & 0.031 \\
\hline Aortic regurgitation $\geq 2$ & 48 & 44.4 & 29 & 65.9 & 0.016 \\
\hline Pericardial effusion & 48 & 44.4 & 20 & 48.8 & 0.635 \\
\hline
\end{tabular}

Abbreviations: ARR, aortic root replacement; LVEF, left ventricular ejection fraction; NYHA, New York Heart Association; SCR, supracoronary aortic replacement.

ARR group and 52 (57.1\%) patients of the SCR group (patients lost to follow-up: ARR group, 7, SCR group, 39). One patient (1.7\%) of the ARR (Yacoub technique) group had significant aortic regurgitation 9.9 years after primary surgery. Seven patients (7.7\%) of the SCR group had significant aortic regurgitation during follow-up within a median period of 3.2 years (IR: $0-4.1$ years). Occurrence of a significant aortic regurgitation $\geq 2$ during follow-up was similar in both groups $(p=0.176)$.

\section{Reoperation of the Distal Aorta}

Freedom from distal aortic reoperation is shown in - Fig. $\mathbf{3 B}$. Distal aortic reoperation includes redo open surgery of the distal aorta and thoracic endovascular aortic repair (TEVAR). Mean period before reoperation of the distal aorta in ARR group and SCR group was $3.23 \pm 2.3$ and $4.2 \pm 4.13$ years $(p=0.166)$, respectively. Three patients of the ARR group underwent open surgery of the aortic arch. Six patients of the 
Table 2 Preoperative imaging data

\begin{tabular}{|c|c|c|c|c|c|}
\hline & \multicolumn{2}{|c|}{ SCR group $(n=118)$} & \multicolumn{2}{|c|}{ ARR group $(n=46)$} & \multirow[t]{2}{*}{$p$-Value } \\
\hline & $n$ & $\%$ & $n$ & $\%$ & \\
\hline Bicarotid trunk artery & 18 & 21.2 & 10 & 26.3 & 0.530 \\
\hline \multicolumn{6}{|c|}{ Primary intimal tear location: } \\
\hline Sinus of Valsalva & 15 & 13.6 & 19 & 43.2 & $<0.0001$ \\
\hline Ascending aorta & 67 & 60.9 & 23 & 52.3 & 0.433 \\
\hline Aortic arch & 19 & 17.3 & 2 & 4.5 & 0.065 \\
\hline Descending aorta & 9 & 8.2 & 0 & 0 & 0.062 \\
\hline \multicolumn{6}{|c|}{ Aortic dissection involving: } \\
\hline Sinus of Valsalva & 67 & 69.1 & 34 & 89.5 & 0.140 \\
\hline Aortic arch & 83 & 85.6 & 34 & 89.5 & 0.548 \\
\hline Descending aorta & 63 & 65.6 & 26 & 68.4 & 0.757 \\
\hline Abdominal aorta & 56 & 58.3 & 21 & 56.8 & 0.869 \\
\hline \multicolumn{6}{|l|}{ Patent false lumen: } \\
\hline Sinus of Valsalva & 51 & 56 & 33 & 86.8 & 0.001 \\
\hline Aortic arch & 66 & 70.2 & 31 & 81.6 & 0.180 \\
\hline Descending aorta & 52 & 55.9 & 26 & 68.4 & 0.186 \\
\hline Abdominal aorta & 48 & 51.6 & 21 & 56.8 & 0.596 \\
\hline
\end{tabular}

Abbreviations: ARR, aortic root replacement; SCR: supracoronary replacement.

Note: 59 patients (35.9\%) of 164 patients of the cohort presented a DeBakey Type 2 dissections.

SCR group underwent distal open arch reoperation and four patients had thoracic endovascular aortic endoprosthesis. There was no difference during follow-up concerning the reoperation of the distal aorta between the two groups $(p=0.623)$.

\section{Risk Factors of Late Mortality}

Univariate analysis was performed with patients alive at hospital discharge (ARR: $n=41$, SCR: $n=91$ ) after primary surgery. Significant preoperative aortic regurgitation $\geq$ grade 2 $(p=0.017)$, aortic valve replacement $(p=0.031)$, postoperative radiologic descending aorta dissection $(p=0.031)$, postoperative radiologic patent false lumen of the aortic arch and the descending aorta $(p=0.029, p=0.038)$, SCR $(p=0.011)$, reoperation of the aortic $\operatorname{arch}(p=0.007)$, and postoperative pulmonary infection $(p=0.005)$ were identified as significant risk factors for late death. Reoperation of the aortic root, recurrent aortic regurgitation $\geq$ grade 2 , and male gender were not a risk factor for late death $(p=0.78,0.084$, and 0.344$)$. Multivariate Cox analysis revealed following two variables as independent factors of late death: (1) reoperation of the aortic arch $(p=0.012,95 \%$ confidence interval $[\mathrm{CI}]: 1.286-7.761)$ and (2) postoperative radiologic patent false lumen of the descending aorta ( $p=0.043,95 \%$ CI: $1.029-6.811)$. Reoperation of the aortic root ( $p=0.189,95 \% \mathrm{CI}: 0.732-11.472)$, recurrent significant aortic regurgitation $\geq$ grade $2(p=0.388,95 \% \mathrm{CI}$ : $0.209-1.838)$, and SCR ( $p=0.09,95 \% \mathrm{CI}: 0.846-10.257)$ were not independent predictors of late mortality.

\section{Radiologic Aortic Diameters Evolution}

Postoperative imaging data were available for 62 (52.5\%) patients of the SCR group and 35 (76.1\%) patients of the ARR group. End-of-follow-up imaging data were available for 56 (47.5\%) patients of the SCR group and 34 (73.9\%) patients of the ARR group. Postoperative and end-of-follow-up radiologic diameters of every different aortic section were compared in each group. Mean and median periods of radiologic follow-up in the SCR group were $4.3 \pm 3.8$ and 3.35 (IR: 0.6-11.1) years, respectively. Mean and median periods of follow-up in the ARR group were $3.69 \pm 2.78$ and 3.8 (IR: 0.8-6) years, respectively. Results are summarized in - Fig. 4A and B. In both groups, no difference was observed between the postoperative imaging data and end-of-followup imaging data, especially concerning the evolution of the sinus of Valsalva diameters in the SCR group. Considering the maximal diameter indexed to the body surface area, ${ }^{11} 33$ presented with aneurysms of the sinus of Valsalva during follow-up, defined as greater than $21 \mathrm{~mm} / \mathrm{m}^{2}$ (ARR group: 6 patients, SCR group: 27 patients, $p=0.003$ ). Among these patients, four had significant aortic regurgitation and belonged to the SCR group.

\section{Discussion}

The primary aim of surgery of TAAD is to prevent aortic rupture with catastrophic bleeding by resecting the primary aortic intimal tear, to correct aortic regurgitation if necessary, and to reestablish a dominant flow in the distal true lumen. Choosing the appropriate surgical procedure remains a surgical dilemma, for both proximal and distal aorta, considering the extent of the aortic dissection, the patient's comorbidities, and the risk of late reoperation. Operative strategies have changed over the decades, with different management policies for the aortic root and the aortic 
72 Type A Aortic Dissection and Aortic Root Surgery Van et al.

Table 3 Intraoperative data

\begin{tabular}{|c|c|c|c|c|c|}
\hline & \multicolumn{2}{|c|}{ SCR group $(n=118)$} & \multicolumn{2}{|c|}{ ARR group $(n=46)$} & \multirow[t]{2}{*}{$p$-Value } \\
\hline & $n$ & $\%$ & $n$ & $\%$ & \\
\hline Cardiopulmonary bypass time (min) & \multicolumn{2}{|c|}{$232.49 \pm 87.11$} & \multicolumn{2}{|c|}{$279.28 \pm 75.79$} & 0.002 \\
\hline Cross-clamping time (min) & \multicolumn{2}{|c|}{$123.30 \pm 49.77$} & \multicolumn{2}{|c|}{$191.91 \pm 47.33$} & $<0.0001$ \\
\hline \multicolumn{6}{|l|}{ Circulatory arrest: } \\
\hline Duration of circulatory arrest (min) & \multicolumn{2}{|c|}{$53.75 \pm 30.99$} & \multicolumn{2}{|c|}{$40.57 \pm 25.65$} & 0.026 \\
\hline Temperature of circulatory arrest $\left({ }^{\circ} \mathrm{C}\right)$ & \multicolumn{2}{|c|}{$20.71 \pm 3.98$} & \multicolumn{2}{|c|}{$23.39 \pm 4.95$} & 0.001 \\
\hline \multicolumn{6}{|l|}{ Cerebral protection during circulatory arrest: } \\
\hline Antegrade perfusion & 29 & 24.8 & 19 & 42.2 & 0.029 \\
\hline Retrograde perfusion & 66 & 56.4 & 15 & 32.6 & 0.006 \\
\hline Deep hypothermia & 10 & 8.5 & 2 & 4.3 & 0.362 \\
\hline Number of dissected sinus of Valsalva & \multicolumn{2}{|c|}{$1.24 \pm 1.20$} & \multicolumn{2}{|c|}{$1.80 \pm 1.22$} & 0.009 \\
\hline \multicolumn{6}{|l|}{ Dissected aortic root structures: } \\
\hline Left coronary sinus & 36 & 31.3 & 25 & 54.3 & 0.006 \\
\hline Right coronary sinus & 31 & 67.4 & 47 & 40.9 & 0.002 \\
\hline Non coronary sinus & 63 & 54.8 & 27 & 58.7 & 0.651 \\
\hline Left coronary artery & 4 & 3.5 & 10 & 21.7 & $<0.0001$ \\
\hline Right coronary artery & 13 & 11.3 & 15 & 32.6 & 0.001 \\
\hline Use of glue in the aortic root & 84 & 71.2 & 0 & 0 & $<0.0001$ \\
\hline \multicolumn{6}{|l|}{ Management of distal anastomosis: } \\
\hline Isolated supracoronary graft & 52 & 67.5 & 25 & 54.3 & 0.236 \\
\hline Hemiarch replacement & 53 & 44.9 & 16 & 34.8 & 0.237 \\
\hline Total arch replacement & 5 & 4.2 & 3 & 6.5 & 0.687 \\
\hline Elephant trunk & 8 & 6.8 & 2 & 4.3 & 0.727 \\
\hline Distal aortic gluing & 60 & 50.8 & 20 & 43.5 & 0.396 \\
\hline \multicolumn{6}{|l|}{ Aortic valve replacement: } \\
\hline Biological prosthesis & 3 & 2.5 & 10 & 21.7 & $<0.0001$ \\
\hline Mechanical prosthesis & 7 & 5.9 & 14 & 30.4 & $<0.0001$ \\
\hline Coronary arteries bypass graft & 5 & 4.2 & 1 & 2.2 & 1 \\
\hline Thoracic endovascular aortic repair & 3 & 2.5 & 0 & 0 & 0.560 \\
\hline
\end{tabular}

Abbreviations: ARR, aortic root replacement; CABG, coronary arteries bypass graft; SCR, supracoronary replacement.

arch. Parikh et al $^{1}$ reports in the International Registry of Acute Aortic Dissection (IRAD) trends toward more extensive surgery of the proximal and distal aorta, using more valvesparing procedures and fewer mechanical aortic prostheses. SCR with valve resuspension is considered as a relatively safe procedure to minimize the perioperative risk of pejorative outcomes. $^{12,13}$ On the other hand, some studies promote ${ }^{14}$ an extensive management of the aortic root during TAAD surgery, primarily to avoid reoperation on the aortic root, with acceptable in-hospital and long-term mortality and low rate of reoperation. But most of the studies reported ARR in relatively young patients below 60 years of age, ${ }^{4,15}$ while the mean age of occurrence of aortic dissection recently reported by Berretta et $\mathrm{al}^{16}$ in the IRAD is 62 years. In our study, mean age of ARR group and SCR were significantly different, and may be the cause of most of the late differences observed between the two groups. ARR technique was also chosen if the aortic root presented structural abnormalities (aortic valve disease, primary intimal tear, and aortic wall defect) as suggested in the guidelines, ${ }^{17}$ regardless of patient's age.

Rate of reoperation on the aortic root in our study was low and was not different between the ARR and SCR groups. In a meta-analysis of 19 studies, comparing conservative versus non conservative management of the aortic root, Saczkowski et $\mathrm{al}^{18}$ reported no difference between the two strategies regarding the late mortality. Moreover, freedom from reoperation on the aortic root and recurrence of significant aortic regurgitation $\geq$ grade 2 at 5 and 10 years were 89 and 79 and 95 and $86 \%$, respectively. These results suggested that SCR was a safe procedure with an acceptably low rate of root complications and root reoperations at 10 -year follow-up, considering the initial surgical issues during primary surgery. ARR technique was identified by some authors ${ }^{14}$ as a protective factor against proximal reoperation, with improved long-term survival, 
Table 4 Postoperative clinical outcomes

\begin{tabular}{|c|c|c|c|c|c|}
\hline & \multicolumn{2}{|c|}{$\begin{array}{l}\text { SCR group } \\
(n=118)\end{array}$} & \multicolumn{2}{|c|}{$\begin{array}{l}\text { ARR group } \\
(n=46)\end{array}$} & \multirow[t]{2}{*}{$p$-Value } \\
\hline & $n$ & $\%$ & $n$ & $\%$ & \\
\hline In-hospital 30-day mortality & 27 & 22.9 & 5 & 11.1 & 0.091 \\
\hline Total length of stay $(\mathrm{d})$ & \multicolumn{2}{|c|}{$10(7-18)$} & \multicolumn{2}{|c|}{$11(10-16)$} & 0.998 \\
\hline Intensive care unit length of stay (d) & \multicolumn{2}{|c|}{$5(2-9)$} & \multicolumn{2}{|c|}{$4(3-8)$} & 0.589 \\
\hline Reoperation for major bleeding & 5 & 4.7 & 3 & 7.5 & 0.684 \\
\hline Mechanical ventilation duration (d) & \multicolumn{2}{|c|}{$5.85 \pm 11.08$} & \multicolumn{2}{|c|}{$3.25 \pm 5.49$} & 0.160 \\
\hline \multicolumn{6}{|l|}{ Neurological outcomes: } \\
\hline Spinal cord ischemia & 3 & 2.7 & 2 & 4.5 & 0.620 \\
\hline Stroke & 10 & 9.1 & 2 & 4.5 & 0.512 \\
\hline Coma & 6 & 5.5 & 0 & 0 & 0.186 \\
\hline Renal failure & 60 & 57.1 & 11 & 27.5 & 0.001 \\
\hline Mediastinitis & 4 & 3.8 & 0 & 0 & 0.576 \\
\hline Pulmonary infection & 15 & 14.4 & 6 & 15 & 0.930 \\
\hline Prolonged mechanical ventilation ( $>3$ days) & 32 & 31.1 & 9 & 22.5 & 0.309 \\
\hline Acute respiratory distress syndrome $\left(\mathrm{PaO}_{2} / \mathrm{FiO}_{2}<200\right)$ & 12 & 11.5 & 4 & 10 & 1 \\
\hline Confusion & 28 & 26.9 & 6 & 15 & 0.131 \\
\hline Mesenteric ischemia/infarction & 12 & 11.7 & 1 & 2.5 & 0.111 \\
\hline Left ventricular ejection fraction (\%) & \multicolumn{2}{|c|}{$60.86 \pm 6.48$} & \multicolumn{2}{|c|}{$60.26 \pm 6.65$} & 0.643 \\
\hline Postoperative aortic regurgitation $\geq 2$ & 6 & 7.6 & 1 & 2.9 & 0.435 \\
\hline
\end{tabular}

Abbreviations: ARR, aortic root replacement; LVEF, left ventricular ejection fraction; SCR, supracommissural replacement. Note: Total length of stay and intensive care unit length of stay are expressed in median and interquartile ranges (25-75\%).

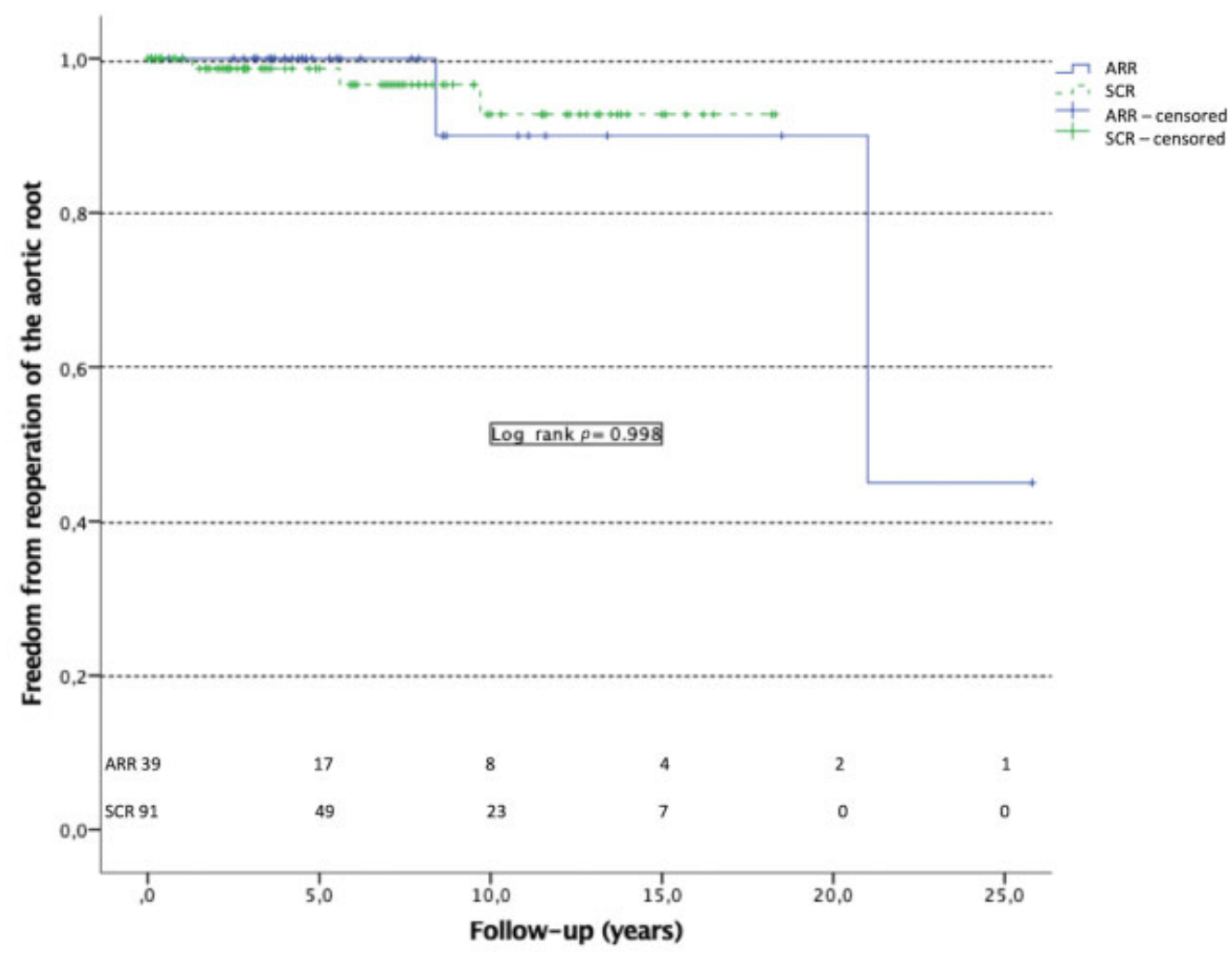

Fig. 1 Freedom from reoperation of the aortic root. Occurrence of reoperation of the aortic root during follow-up was assessed in patients alive at discharge from hospital after primary operation. ARR, aortic root surgery; SCR, supracoronary replacement. 

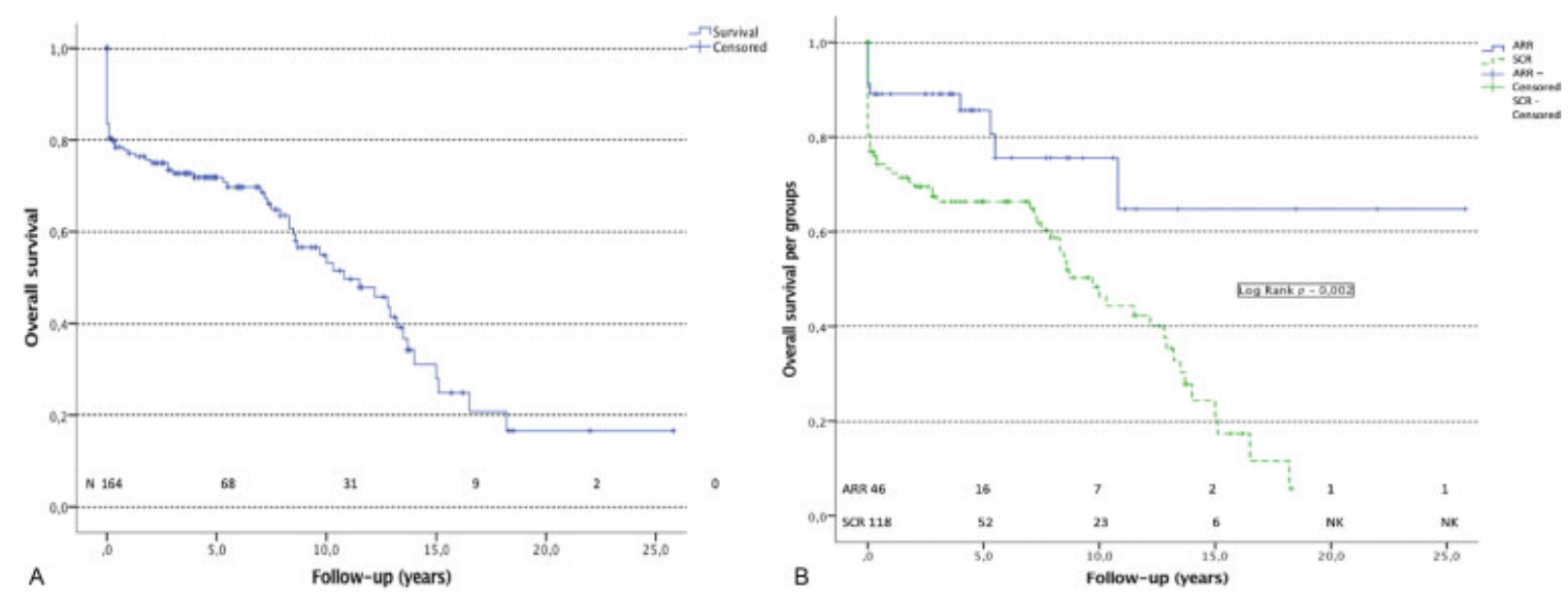

Fig. 2 Kaplan-Meier analysis of the survival. (A) Overall survival, (B) overall survival per group. Overall survival analysis includes patients who died within 30 days after surgery and patients alive at discharge from hospital. ARR, aortic root replacement; SCR, supracoronary replacement.
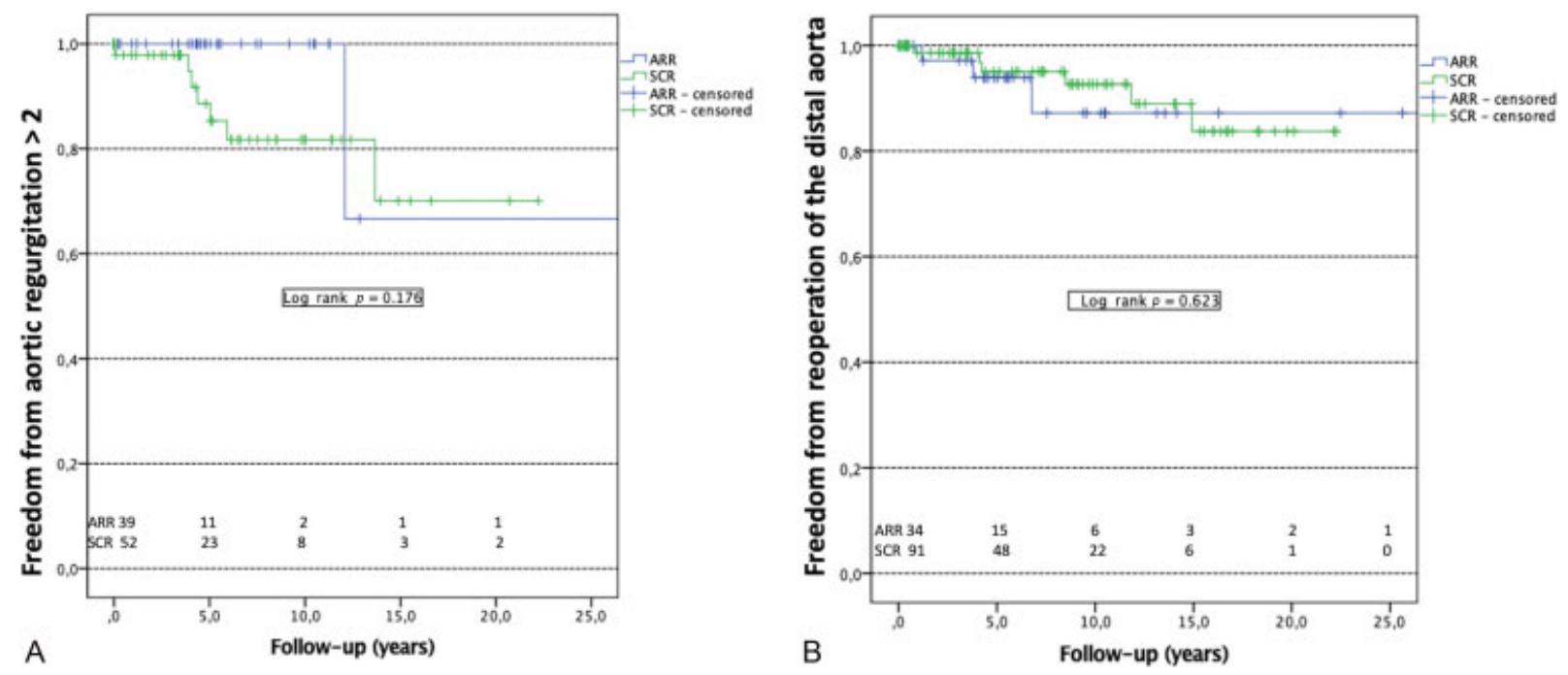

Fig. 3 Aortic regurgitation $\geq$ grade 2 and reoperation of the distal aorta during follow-up. Occurrence during follow-up of significant aortic regurgitation $\geq$ grade 2 (A) and reoperation on the distal aorta (B) is analyzed in patients alive after primary surgery of Type A aortic dissection (patients who died within the 30 days after surgery are excluded from the present analysis). ARR, aortic root replacement; SCR: supracoronary replacement.
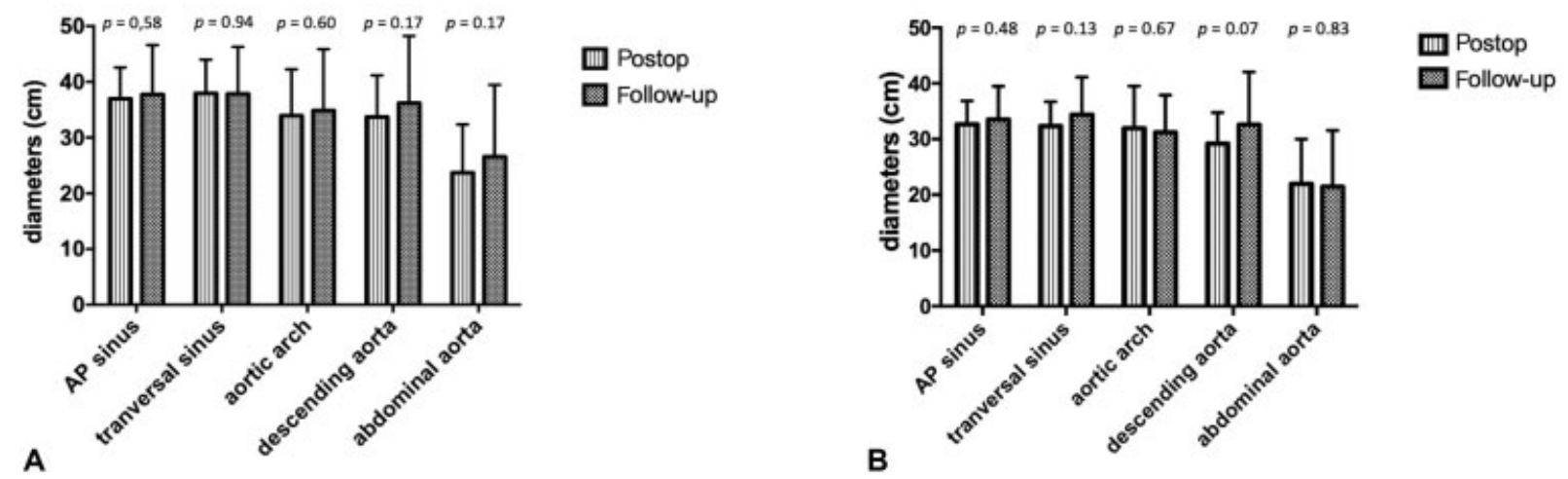

Fig. 4 Evolution of radiologic aortic diameters at end of follow-up. (A) SCR group analysis, (B) ARR group analysis. Aortic radiologic diameters were compared in different sections of the aorta between early postoperative imaging and follow-up imaging. AP sinus: anteroposterior sinus diameter; ARR: aortic root replacement; Post-op, postoperative; SCR, supracoronary replacement. 
avoiding the long-term problems of the SCR technique., ${ }^{2,19}$ Reoperation on the aortic root after primary TAAD surgery remains risky, with early mortality of 11.1 to $14.3 \% .^{5,7}$

However, extensive management of the aortic root during primary surgery, by consensus, should be performed in cases of aortic dissection with underlying connective tissue disorder like Marfan syndrome, ${ }^{20}$ and should be considered in young patients. ${ }^{15}$

Concerning radiologic diameter evolution of the aortic root after TAAD surgery, only a few studies analyzed and compared aortic root diameters between the postoperative and the followup period. Ro et $\mathrm{a}^{21}$ determined that a maximal preoperative root diameter $>45 \mathrm{~mm}$ was an independent predictor of the composite endpoint of aortic regurgitation and root dilatation during follow-up. Assessment of the indexed diameter of the sinus of Valsalva ${ }^{11}$ was added in our study, so as not to underestimate the number of patients (despite an aortic root diameter $<45 \mathrm{~mm}$ ) still harbor a substantial aortic root enlargement compared with body size.

New-onset aortic regurgitation $\geq$ grade 2 is more frequent in the SCR group than in ARR group. This incidence may be underestimated in the SCR group because of scarcity of echocardiographic data available during follow-up (57.1\% patients). A few studies ${ }^{21}$ report incidence from 3 to $4.3 \%$ of significant aortic regurgitation during follow-up.

\section{Limitations}

This is a historical monocentric retrospective study of patients who were operated from TAAD and did not consider surgical evolution during the two decades of follow-up techniques incorporated in our practice, especially concerning the growing number of valve-sparing root operations. Follow-up percentages are short of complete, but realistic for a study of this duration.

\section{Conclusion}

TAAD surgery with a conservative approach is an effective strategy in terms of reoperation of the aortic root, although ARR improved overall survival (possibly because the ARR group was much younger).

Funding

None.

Conflict of Interest

The authors declare no conflict of interest related to this article.

Acknowledgments

None

\section{References}

1 Parikh N, Trimarchi S, Gleason TG, et al. Changes in operative strategy for patients enrolled in the International Registry of Acute Aortic Dissection interventional cohort program. J Thorac Cardiovasc Surg 2017;153(04):S74-S79
2 Kallenbach K, Oelze T, Salcher R, et al. Evolving strategies for treatment of acute aortic dissection Type A. Circulation 2004;110 (11, Suppl 1):II243-II249

3 Montalvo J, Razzouk A, Wang N, et al. Aortic root surgery does not increase the operative risk of acute Type A aortic dissection. Am Surg 2011;77(01):88-92

4 Kunihara T, Neumann N, Kriechbaum SD, Aicher D, Schäfers HJ. Aortic root remodeling leads to good valve stability in acute aortic dissection and preexistent root dilatation. J Thorac Cardiovasc Surg 2016;152(02):430-436.e1

5 Esaki J, Leshnower BG, Binongo JN, et al. Reoperative aortic root replacement: outcome in a contemporary series. J Thorac Cardiovasc Surg 2017;154(03):800-808.e3

6 Subramanian S, Leontyev S, Borger MA, Trommer C, Misfeld M, Mohr FW. Valve-sparing root reconstruction does not compromise survival in acute Type A aortic dissection. Ann Thorac Surg 2012;94(04):1230-1234

7 Estrera AL, Miller CC III, Villa MA, et al. Proximal reoperations after repaired acute Type A aortic dissection. Ann Thorac Surg 2007;83(05):1603-1608, discussion 1608-1609

8 de Brux JL, Subayi JB, Pegis JD, Pillet J. Retrograde cerebral perfusion: anatomic study of the distribution of blood to the brain. Ann Thorac Surg 1995;60(05):1294-1298

9 David TE, Feindel CM. An aortic valve-sparing operation for patients with aortic incompetence and aneurysm of the ascending aorta. J Thorac Cardiovasc Surg 1992;103(04):617-621, discussion 622

10 Sarsam MA, Yacoub M. Remodeling of the aortic valve anulus. J Thorac Cardiovasc Surg 1993;105(03):435-438

11 Roman MJ, Devereux RB, Kramer-Fox R, O'Loughlin J. Two-dimensional echocardiographic aortic root dimensions in normal children and adults. Am J Cardiol 1989;64(08):507-512

12 Westaby S, Saito S, Katsumata T. Acute Type A dissection: conservative methods provide consistently low mortality. Ann Thorac Surg 2002;73(03):707-713

13 Sievers HH, Richardt D, Diwoky M, et al. Survival and reoperation after valve-sparing root replacement and root repair in acute Type $A$ dissection. J Thorac Cardiovasc Surg 2018;156(06):2076-2082.e2

14 Hysi I, Juthier F, Fabre O, et al. Aortic root surgery improves longterm survival after acute Type A aortic dissection. Int J Cardiol 2015;184:285-290

15 Di Eusanio M, Trimarchi S, Peterson MD, et al. Root replacement surgery versus more conservative management during Type A acute aortic dissection repair. Ann Thorac Surg 2014;98(06):2078-2084

16 Berretta P, Patel HJ, Gleason TG, et al. IRAD experience on surgical Type A acute dissection patients: results and predictors of mortality. Ann Cardiothorac Surg 2016;5(04):346-351

17 Erbel R, Aboyans V, Boileau C, et al; ESC Committee for Practice Guidelines The Task Force for the Diagnosis and Treatment of Aortic Diseases of the European Society of Cardiology (ESC) 2014 ESC Guidelines on the diagnosis and treatment of aortic diseases: document covering acute and chronic aortic diseases of the thoracic and abdominal aorta of the adult. Eur Heart J 2014;35 (41):2873-2926

18 Saczkowski R, Malas T, Mesana T, de Kerchove L, El Khoury G, Boodhwani M. Aortic valve preservation and repair in acute Type A aortic dissection. Eur J Cardiothorac Surg 2014;45(06):e220-e226

19 Halstead JC, Spielvogel D, Meier DM, et al. Composite aortic root replacement in acute Type $A$ dissection: time to rethink the indications? Eur J Cardiothorac Surg 2005;27(04):626-632, discussion 632-633

20 Rylski B, Bavaria JE, Beyersdorf F, et al. Type A aortic dissection in Marfan syndrome: extent of initial surgery determines long-term outcome. Circulation 2014;129(13):1381-1386

21 Ro SK, Kim JB, Hwang SK, et al. Aortic root conservative repair of acute Type A aortic dissection involving the aortic root: fate of the aortic root and aortic valve function. J Thorac Cardiovasc Surg 2013;146(05):1113-1118 